\title{
Amphiregulin Regulates Differentiation of Dental Pulp Stem Cells by Activation of Mitogen-activated Protein Kinase and the Phosphatidylinositol 3- kinase Signaling Pathways
}

\section{Wenxi He ( $\nabla$ hewenxi7725@163.com )}

Fourth Military Medical University: Air Force Medical University https://orcid.org/0000-0002-5353-0465

Junqing Li

Zunyi Medical University

\section{Zhihua Wang}

Fourth Military Medical University School of Stomatology: Air Force Medical University School of Stomatology

\section{Juan Wang}

Fourth Military Medical University School of Stomatology: Air Force Medical University School of Stomatology

\section{Qian Guo}

Fourth Military Medical University School of Stomatology: Air Force Medical University School of Stomatology

Yi Fu

Zunyi Medical College: Zunyi Medical University

\section{Zihan Dai}

Fourth Military Medical University School of Stomatology: Air Force Medical University School of Stomatology

\section{Minghao Wang}

Fourth Military Medical University School of Stomatology: Air Force Medical University School of Stomatology

\section{Yu Bai}

Fourth Military Medical University School of Stomatology: Air Force Medical University School of Stomatology

\section{Xin Liu}

Fourth Military Medical University School of Stomatology: Air Force Medical University School of Stomatology

\section{Paul Cooper}

University of Otago Department of Oral Sciences 


\section{Research Article}

Keywords: Cell differentiation, Signal transduction, Tissue regeneration

Posted Date: January 18th, 2022

DOI: https://doi.org/10.21203/rs.3.rs-1179945/v1

License: (c) (1) This work is licensed under a Creative Commons Attribution 4.0 International License. Read Full License 


\section{Abstract}

Background: Human dental pulp stem cells (hDPSCs) have received widespread attention in the fields of tissue engineering and regenerative medicine. Although amphiregulin (AREG) has been shown to play a vital function in the biological processes of various cell types, its effects on DPSCs is still unknown. The aim of this study was to explore the specific role of AREG as a biologically active factor in the regeneration of dental pulp tissue.

Methods: The growth of hDPSCs, together with their proliferation and apoptosis, in response to AREG was examined by CCK-8 assay and flow cytometry. We explored the effects of AREG on osteo/odontogenic differentiation in vitro and investigated the regeneration and mineralization of hDPSCs in response to AREG in vivo. The effects of AREG gain-and loss-of-function on DPSC differentiation were investigated following transfection using overexpression plasmids and shRNA, respectively. The involvement of the mitogen-activated protein kinase (MAPK) or phosphatidylinositol 3kinase (PI3K)/Akt pathways in the mineralization process and expression of odontoblastic marker proteins after AREG induction was investigated by using Alizarin Red S staining and western blotting.

Results: AREG $(0.01-0.1 \mu \mathrm{g} / \mathrm{mL})$ treatment of hDPSCs from 1 to 7 days minimally increased hDPSCs growth and marginally affected apoptosis compared with negative controls. AREG exposure significantly promoted hDPSCs differentiation, shown by increased mineralized nodule formation and the expression of odontoblastic marker protein expression. In vivo micro-CT imaging and quantitative analysis showed significantly greater formation of highly mineralized tissue in the $0.1 \mu \mathrm{g} / \mathrm{mL}$ AREG exposure group in DPSC/NF-gelatin-scaffold composites. AREG also promoted extracellular matrix production, with collagen fiber, mineralized matrix, and calcium salt deposition on the composites, as shown by H\&E, Masson, and Von Kossa staining. Furthermore, AREG overexpression boosted hDPSCs differentiation while AREG silencing inhibited it. During the differentiation of DPSCs, AREG treatment led to phosphorylation of extracellular signal-regulated kinase (ERK), c-Jun N-terminal kinase (JNK), and PI3K/Akt. Notably, a specific inhibitor of ERK, JNK, and PI3K/Akt signaling markedly reduced AREGinduced differentiation, as well as levels of phosphorylated ERK and JNK in hDPSCs.

Conclusions: Data indicated that AREG enabled odontoblastic differentiation and facilitated the regeneration and mineralization processes in hDPSCs.

\section{Background}

Mesenchymal stem cells (MSCs) are multifunctional cells found in various tissues, including bone marrow, bone, adipose tissue, Wharton's jelly, umbilical cord blood and peripheral blood, that can be used for cell therapy or organ regeneration [1-2]. Dental pulp stem cells (DPSCs) isolated from human dental pulp tissues, are specific mesenchymal stem cells that can be induced to differentiate into odontoblasts in vitro or to form dentine-/pulp-like tissue in vivo [3-6]. DPSCs are relatively easy to obtain from waste tissue and demonstrate higher levels of proliferation, clonal potential, and mineralization than bone 
marrow mesenchymal stem cells (BMMSCs) [7]. Consequently, DPSCs have received widespread attention in the fields of tissue engineering and regenerative medicine. Despite this, signal transduction mechanisms involved in the oriented differentiation of DPSC are not yet fully understood.

Growth factor signaling plays pivotal regulatory roles in cell growth and differentiation. As amphiregulin (AREG) is a member of the epidermal growth factor (EGF) family, and is expressed by a variety of epithelial and mesenchymal cell types during development and in homeostasis [8-9]. Recently, AREG has been shown to play vital roles in regulating a broad range of biological processes, including cell growth, proliferation, nerve formation, cell migration and bone formation, by binding to the EGF receptor (EGFR) on the cell membrane [10]. Interestingly, AREG can regulate squamous cell differentiation and neuronal differentiation from stem/progenitor cell sources [11-12]. AREG has also been found to accumulate in multiple myeloma-derived exosomes and is involved in osteoclast differentiation through a circuitous mechanism in osteoblasts [13]. While, AREG appears to be an important growth factor in regulating the differentiation of a variety of cell types its effects on the growth and differentiation of DPSCs is still unknown.

AREG was first identified in the culture supernatants of the human breast cancer cell line MCF-7 [14] and was found to bind to EGFR to activate downstream signaling pathways. Indeed, it is known to activate a variety of downstream intracellular signaling pathways, including Ras/MAPK, PI3K/AKT, mTOR, and STAT [15-16]. These signal transduction cascades regulate gene expression and initiate diverse cellular responses, including proliferation, survival, invasion, differentiation, and angiogenesis. AREG can promote migratory activity and doxorubicin resistance through activation of the MAPK pathway [17]. Furthermore, AREG-induced growth can also be regulated partially through the MAPK and PI3K-Akt/PKB pathways [18]. Currently, the role of AREG on activating downstream signaling in the regeneration of dental pulp tissue is not known. Therefore, our study aimed to explore the effects of AREG on growth, differentiation, and regeneration processes of DPSCs.

\section{Methods}

\section{Reagents}

Amphiregulin (AREG) (262-AR-100) was obtained from R\&D Systems (R\&D, CA, USA). The specific inhibitors of ERK kinase, p38 kinase, JNK kinase, and AKT kinase are U0126, SB203580, SP600125, and LY294002, respectively, were all obtained from Cell Signaling Technology (Danvers, MA, USA). AREG lentivirus kits were from Hanbio Biotechnology (Hanbio, China).

\section{DPSC culture}

Freshly extracted sound teeth were collected from patients (18-22-years-old), under the approval of the Ethics Committee of the Fourth Military Medical University (FMMU), Xi'an, China with informed consent. The hDPSCs were isolated, cultured, and identified as previously described [19-20]. Briefly, 
the pulp tissue was dissected and digested with $3 \mathrm{mg} / \mathrm{mL}$ type I collagenase and $4 \mathrm{mg} / \mathrm{mL}$ dispase (Sigma Aldrich, St Louis, MO, USA) for $45-60 \mathrm{~min}$ at $37^{\circ} \mathrm{C}$. Single-cell suspensions were cultured in $60-$ $\mathrm{mm}$ culture dishes and maintained in a-minimum essential medium (a-MEM; Invitrogen, Carlsbad, CA, USA) with $10 \%$ (v/v) fetal bovine serum (Gibco-BRL, Grand Island, NY, USA), 100 units $/ \mathrm{mL}$ penicillin-G, and $100 \mathrm{mg} / \mathrm{mL}$ streptomycin (Invitrogen) in a humidified atmosphere with $5 \% \mathrm{CO}_{2}$ at $37^{\circ} \mathrm{C}$. Single-cell clones of DPSCs were isolated and passaged as previously described [21]. DPSCs were grown in a $5 \%$ $\mathrm{CO}_{2}$ incubator at $37^{\circ} \mathrm{C}$ and cultures at passages 3-5 were used for all studies.

\section{Multi-lineage differentiation in vitro}

Cells were cultured in 6-well plates in osteo/odontogenic induction medium containing $50 \mathrm{mg} / \mathrm{ml}$ ascorbic acid, $10 \mathrm{mM}$ ß-glycerophosphate, and $10 \mathrm{nM}$ dexamethasone (all from Sigma- Aldrich) with 10\% FBS for 14 days. Cultures were washed twice in PBS and fixed with $4 \%$ polyoxymethylene (SigmaAldrich) for $15 \mathrm{~min}$. Cultures were then stained with Alizarin Red S (Sigma-Aldrich). For adipogenic induction, the cells were cultured in adipogenic induction medium containing $1 \mathrm{mM} \mathrm{IBMX}, 0.4 \mathrm{mM}$ indomethacin, $0.2 \mu \mathrm{M}$ dexamethasone, $0.02 \mathrm{mg} / \mathrm{mL}$ insulin, $100 \mu \mathrm{g} / \mathrm{mL}$ streptomycin, $100 \mathrm{U} / \mathrm{mL}$ penicillin, and $10 \%$ FBS a-MEM medium) for 21 days. Cultures were stained with $0.3 \%(\mathrm{w} / \mathrm{v})$ Oil-Red 0 (Sigma-Aldrich)/60\% isopropanol reagent for $60 \mathrm{~min}$. Finally, the cultures were washed three times in water prior to analysis.

\section{Flow cytometric analysis of stem cell surface markers}

DPSC $\left(2 \times 10^{5}\right.$ cells $)$ were digested by trypsinization and harvested. Cells $\left(1 \times 10^{6} / 100 \mu \mathrm{l}\right)$ were resuspended and incubated with fluorescein isothiocyanate (FITC)-coupled anti-human monoclonal antibodies against CD105-FITC, CD34-PE, CD45-PE, CD90-PE, CD29-PE and CD146-PE (1: 100 dilution; BD Biosciences, San Jose, $\mathrm{CA}, \mathrm{USA}$ ) in PBS with $3 \% \mathrm{FBS}$ for $1 \mathrm{~h}$ in the dark at room temperature. Finally, the samples were analyzed on a flow cytometer (FACS Calibur; BD Biosciences) using the CellQuest PROTM software (BD Biosciences).

\section{Flow cytometric analysis of proliferation and apoptosis in hDPSCs}

Third-passage DPSCs $\left(3 \times 10^{6} \mathrm{cells} / \mathrm{dish}\right)$ were inoculated in $60 \mathrm{~mm}$ dishes. The experimental groups were treated with $0.01 \mu \mathrm{g} / \mathrm{mL}$ and $0.1 \mu \mathrm{g} / \mathrm{mL}$ AREG for $16 \mathrm{~h}$, respectively. The control group received no AREG treatment. After removal from the dishes, cells were washed three times in pre-cooled phosphate-buffered saline (PBS) and were fixed in 75\% ice-cold ethanol. A flow cytometer (BD Biosciences, San Jose, CA, USA) was used to monitor the changes in the G0/G1, S, and G2/M phases of the cell cycle and to calculate the cell proliferation index $(\mathrm{PI}=\mathrm{G} 2 / \mathrm{M}+\mathrm{S})$. For the measurement of apoptosis, the AREG-treated 
DPSCs were harvested and washed as above, and $500 \mu \mathrm{l}$ of cells was diluted with $1 \times$ Annexin V Binding Buffer working solution according to the instructions of the apoptosis kit (KeyGENBioTECH, China). Then, $5 \mu \mathrm{l}$ Annexin V-APC and 5 $\mu \mathrm{l}$ 7-ADD staining solution were added to the cells and the number of apoptotic cells was detected by FCM.

\section{Cell counting kit-8 assay (CCK-8)}

Five thousand DPSCs per well were seeded and cultured in 96-well plates with different concentrations of AREG $(0-1 \mu \mathrm{g} / \mathrm{mL})$. In a separate experiment, DPSCs were incubated with $20 \mu \mathrm{l}$ CCK-8 reagents (KeyGENBioTECH, China) at $37^{\circ} \mathrm{C}$ for $2 \mathrm{~h}$ for 1, 3, 5, and 7 days. Finally, absorbances at $450 \mathrm{~nm}$ were read in a microplate reader (ModelELX 808; Bio-Tek, Winooski, VT, USA).

\section{Alizarin Red S staining and quantitation}

DPSCs $\left(4 \times 10^{5}\right.$ cells/well) were seeded into 6-well plates and cultured in either control medium or osteo/odontogenic induction medium with AREG for 14 days. At specified time, the cells were fixed in 1 $\mathrm{ml}$ of $4 \%$ paraformaldehyde for $30 \mathrm{~min}$ at room temperature. After three washes with distilled water, $0.1 \mathrm{~g} / \mathrm{ml}$ Alizarin Red S (ARS) (Sigma-Aldrich) was used to stain the cultures for $10 \mathrm{~min}$ at room temperature. The unbound stain was removed by washing with deionized water until the discarded liquid appeared colorless. Five hundred microliters of water were added to each dish to keep the cells hydrated, and the cells were observed under Olympus inverted microscopy (Tokyo, Japan). For quantitation, alizarin red stain dissolved in 10\% cetylpyridinium chloride (CPC) (Sigma-Aldrich) was added to the cells and the absorbance at $450 \mathrm{~nm}$ was read in the microplate reader.

\section{In vivo studies}

All animal surgical procedures were approved by the Animal Care Committee and the Institutional Review Board (IRB) for Human Subjects Research of the Fourth Military Medical University. The high-stiffness three-dimensional (3D) nanofibrous gelatin (NF-gelatin) scaffolds were a kind gift from Prof. Tiejun Qu [22]. Initially, the NF-gelatin scaffolds were placed in $70 \%$ alcohol for half an hour and then washed three times in sterile PBS to remove residual ethanol. Before the seeding of human DPSCs $\left(5 \times 10^{5}\right)$, the scaffolds were soaked in a-MEM containing $10 \%$ FBS. The cell-scaffold composites were cultured in aMEM supplemented with $10 \%$ FBS for $24 \mathrm{~h}$ on an orbital shaker (Orbi-shaker ${ }^{\text {TM }}$, Benchmark, USA) in an incubator with $5 \% \mathrm{CO}_{2}$ at $37^{\circ} \mathrm{C}$. Subsequently, the cell-scaffold composites were stimulated with $0.1 \mu \mathrm{g} / \mathrm{mL}$ AREG in osteo/odontogenic induction medium for 7 days. Controls received no AREG exposure. The medium was changed every other day. After 7 days, the cell-scaffold composites were implanted subcutaneously on the dorsal surfaces of immune-compromised nude mice (nu/nu, 6-8 weeks old). After 4 weeks, the mice were euthanized by an anesthetic overdose and tissue growth was then harvested. Tissue samples were then immediately fixed in $4 \%$ paraformaldehyde overnight. The 
samples ( $\mathrm{n}=4$ in each group) were scanned and analyzed using a micro-CT (eXplore Locus SP micro-CT; GE Healthcare, USA) as previously described [23] and the 3D micro-architectural properties of specimens were evaluated using analysis software (MicroView; GE Healthcare). After decalcification in 17\% ethylenediamine tetra-acetic acid, hematoxylin-eosin (H\&E), Masson's trichrome and von Kossa staining was used for histological observation.

\section{Overexpression and knockdown of $A R E G$ in DPSCs}

AREG- green fluorescent protein lentivirus kits and their respective control kits were purchased from Hanbio (China). DPSCs were transfected with AREG lentivirus according to the manufacturer's instructions. In brief, third-passage DPSCs were inoculated in 12-well plates at $0.5 \times 10^{5} / \mathrm{mL}$ and infected for $4 \mathrm{~h}$, after which $0.5 \mathrm{~mL}$ fresh complete medium was added. After a further $24 \mathrm{~h}$ infection period, the medium was replaced with $1 \mathrm{~mL}$ fresh medium and after a further $72 \mathrm{~h}$, the transfection rate was examined under a fluorescence microscope (DMI8, Leica, German). Puromycin was used to select stably transfected cells with the puromycin concentration determined in a preliminary experiment. For simplicity, AREG-overexpressing and AREG-silenced cells were referred to as AREG (+) and AREG (-), respectively. The effects on the oriented differentiation of DPSCs were examined by ARS and Western blot analysis as described below.

\section{Western blot analysis}

DPSCs were cultured in serum-free medium for $24 \mathrm{~h}$ and were treated with $0.1 \mu \mathrm{g} / \mathrm{mL}$ AREG for $0,30,60$, and $90 \mathrm{~min}$ in the presence or absence of the specific inhibitors U0126 $(25 \mu \mathrm{M})$, SP600125 $(25 \mu \mathrm{M})$, SB203580 $(25 \mu \mathrm{M})$, and LY294002 $(10 \mu \mathrm{M})$. Protein extraction from the cells, SDS-PAGE, and blotting were performed as previously described (17).After incubating with secondary antibodies(1:4000; Santa Cruz Biotechnology, SantaCruz, CA) for $1 \mathrm{~h}$,the protein bands were imaged by using an enhanced chemilumine scence system (Amersham, Piscataway, NJ, USA).

\section{Statistical analysis}

All experiments were repeated separately in triplicate or quintuplicate. Data are expressed as means $\pm S D$. For statistical processing, we used SPSS software 16.0 (version 16.0; SPSS, Chicago, IL, USA). Inter-group differences were compared by the ONE-test. $P<0.0 .5$ was considered to be statistically significant.

\section{Results}

\section{Culture and characterization of hDPSCs}


Fibroblast-like clonal cells were obtained from the dental pulp tissue by limiting dilution and colony cloning (Fig. 1A a and b). Putative stem cells derived from the clonal cells (Fig. 1A c) were characterized by multiple lineage differentiation tests and flow cytometry. If cultured under inductive conditions, the cells formed mineral nodules and lipid droplets, shown by Alizarin Red and Oil Red 0 staining (Fig. 1B a and b). Flow cytometry analysis showed that CD90, CD105, CD29, CD146 and STRO-1 were highly expressed in isolated cultured DPSCs (Fig.1C d-h). In contrast, the hematopoietic cell markersCD34 and CD45 (Fig. 1C b and c) were detected at minimal levels in the cultured stem cells. The morphology, colony formation, immunophenotype and ability to differentiate into multiple lineages, indicated that mesenchymal stem cells had been isolated.

\section{Effects of AREG on growth of hDPSCs}

The effects of AREG on hDPSCs numbers after1-, 3-, 5-, and 7-days incubation were assessed using the CCK-8 assay (Fig. 2A). Data demonstrated that cell numbers in the $0.01 \mu \mathrm{g} / \mathrm{mL}$ and $0.1 \mu \mathrm{g} / \mathrm{mL}$ AREGtreated groups were significantly increased $(P<0.05)$. In contrast, cell numbers in the $1 \mu \mathrm{g} / \mathrm{mL}$ AREGtreated group were reduced. Cell cycle analysis showed a marginal increase in the proliferation index in the $0.01 \mu \mathrm{g} / \mathrm{mL}$ and $0.1 \mu \mathrm{g} / \mathrm{mL}$ AREG exposure groups (PI = G2/M+S), whereas treatment with $1 \mu \mathrm{g} / \mathrm{mL}$ AREG decreased the proliferation index in comparison with the control group (CTRL) (Fig. 2B). In addition, FCM analysis showed that AREG did not significantly affect apoptosis of DPSCs compared with the CTRL group (Fig.2C).

\section{Effects of AREG on odontogenic differentiation of hDPSCs in vitro}

After two weeks of osteo/odontogenic induction, it was apparent that AREG concentrations between 0.01 and $0.1 \mu \mathrm{g} / \mathrm{mL}$ promoted mineralized nodule formation in a dose-dependent manner, although a significant decrease was apparent at $1 \mu \mathrm{g} / \mathrm{mL}$ AREG exposure (Fig. 3A and B).

Consequently, $0.1 \mu \mathrm{g} / \mathrm{mL}$ AREG exposure was selected as the optimal concentration for the following studies to investigate the influence of AREG on DPSCs. When the expression of odontoblastic marker proteins was examined by western blotting, it was found that the levels of DSPP, BSP, RUNX2, and OCN were noticeably up-regulated in the AREG-treated groups compared with the controls by day 3 . Levels were markedly elevated on days 7 and $14(P<0.05)$ (Fig. $3 C$ and D). Taken together, these results indicated that AREG could stimulate DPSC differentiation.

\section{Effects of AREG on regeneration and mineralization of hDPSCs in vivo}


To analyse regeneration capability in response to AREG, the cell-scaffold composites were subcutaneously implanted into nude mice. Subsequently, the specimens were scanned and images reconstructed by using micro CT analysis (Fig. $4 \mathrm{~A}$ and B). Micro-CT images showed the formation of more highly mineralized tissue formed in the $0.1 \mu \mathrm{g} / \mathrm{mL}$ AREG exposure group in the composites (Fig. $4 \mathrm{~A} a$ and $\mathrm{b}$ ). Additionally, quantitative analysis also indicated that the bone volume fraction, trabecular thickness, and trabecular number were superior in the AREG group compared with the control group, although the trabecular separation was decreased (Fig. 4B a-d). All supported AREG enhancing odonto/osteogenic potential of the DPSCs.

The results of the H\&E and Masson staining showed that the cell-scaffold composites stimulated by $0.1 \mu \mathrm{g} / \mathrm{mL}$ AREG produced greater DPSC penetration into the pores of scaffold, as well as showing greater extracellular matrix secretion and collagen fiber wrapping in the NF-gelatin scaffold, compared with the control group (Fig. 4C a, b, d, e, g, h). Von Kossa staining confirmed the presence of mineralization and further demonstrated greater deposition of mineralized matrix and calcium salts in the AREG group (Fig. $4 \mathrm{C} \mathrm{c}, \mathrm{f}, \mathrm{i}$ ). Data confirmed that AREG promoted the regeneration and mineralization capability of hDPSCs in vivo.

\section{Effects of AREG over-expression and knockdown on hDPSCs differentiation}

To further investigate AREG function during DPSC differentiation, cells were transfected with the AREG vector to induce AREG overexpression. Western blotting demonstrated increased expression of the odontoblastic markers at 3,7 , and14 days after induction compared with the control group (Fig. 5C and D). Furthermore, overexpression of $A R E G$ promoted mineralized nodule formation in DPSCs as detected by ARS staining and quantitation (Fig. $5 \mathrm{~A}$ and $\mathrm{B}$ ). These data supported the ability of AREG to promote the differentiation of DPSCs.

To investigate whether AREG up-regulation was necessary for DPSC differentiation, AREG expression was silenced by shRNA transfection in DPSCs. Silencing was confirmed by qRT-PCR at $72 \mathrm{~h}$ after transfection with puromycin selection. Protein expression of DPSC odontoblast markers was decreased in response to AREG inhibition, as shown by Western blotting (Fig. 5E and F). ARS staining and quantitation showed that AREG silencing attenuated mineralized nodule formation in DPSCs (Fig. 5A and B). These results indicated that decreasing $A R E G$ expression resulted in the suppression of odontoblast differentiation.

\section{Involvement of MAPK signaling in AREG-induced differentiation of hDPSCs}

Treatment with AREG increased the protein level of p-ERK after 60 min stimulation. AREG stimulation also resulted in phosphorylated JNK in DPSCs in a time-dependent manner (Fig. 6A and B). However, AREG 
showed minimal effects on phosphorylated p38 (Fig. 6A and B). Notably, incubation with the ERK, JNK, and MAPK inhibitors markedly antagonized the effect of AREG on phosphorylated ERK and JNK in hDPSCs (Fig. 6C and D). These inhibitors also reduced the expression of the mineralization markers assayed by day 14 , and mineralized nodule formation in DPSCs (Fig. 6E-H). Combined, these data indicated that the ERK, JNK, and MAPK pathways are implicated in AREG-induced differentiation of hDPSCs.

\section{Involvement of PI3K/AKT signaling in AREG-induced differentiation of hDPSCs}

AREG phosphorylated AKT in DPSCs in a time-dependent manner (Fig. 6A and B); this effect was inhibited by the PI3K pathway inhibitor LY294002 (Fig. 6C and D). Furthermore, Western blot data showed the levels of DSPP, BSP, RUNX2, and OCN were markedly reduced in cells treated with AREG + LY204002 $(P<0.05)$ (Fig. 6G and H). The PI3K pathway inhibitor LY294002 also markedly antagonized mineralized nodule formation and mineralization markers expression in DPSCs (Fig. 4E-H). These findings suggest that the PI3K/AKT pathways are involved in the AREG-induced differentiation of hDPSCs.

\section{Discussion}

DPSC are a cellular reservoir, and have been shown to have considerable important applications in several different fields of tissue engineering. As with other somatic stem cells, a variety of studies have verified the potential of DPSCs in regenerative therapies, based on their multipotent differentiation capability [24]. Importantly, their cell growth and differentiation cannot be separated from the regulatory action of stimulatory growth factors and numerous studies have demonstrated the importance of the EGF family in developmental regulation processes [25-26]. EGF is known to exert its biological actions through its binding to EGFR on cell surfaces and amphiregulin (AREG) is also able to interact with the same receptor to activate downstream signaling pathways [10]. In the present study, the results indicated that AREG was able to promote odontoblastic differentiation in hDPSCs through the activation of the ERK, JNK, MAPK, and PI3K/Akt pathways, and facilitated the regeneration and mineralization of hDPSCs. This action may have potential to be harnessed for the development of novel strategies for the repair of damaged pulp and tissue regeneration.

A previous study demonstrated that AREG was able to inhibit or induce cell growth and proliferation in a range of cell types [14]. For example, AREG can induce a potent proliferative response in colon carcinoma cells [27] and it can also increase proliferation in airway epithelial and smooth muscle cells [28]. AREG also plays a vital function in skin wound healing by stimulating keratinocyte proliferation [29-32].

Furthermore, it has been reported that overexpression of AREG induced self-sufficient growth and survival in lung, liver, colon, breast, and pancreatic carcinoma cells [10,33-37]. In the present study, we identified a biphasic effect of AREG. Data demonstrated that the numbers of hDPSCs treated with $0.01 \mu \mathrm{g} / \mathrm{mL}$ and $0.1 \mu \mathrm{g} / \mathrm{mL}$ AREG were significantly increased after 3,5 , and 7 days of treatment while exposure to higher 
dose of $1 \mu \mathrm{g} / \mathrm{mL}$ AREG reduced cell numbers by day 7 . The analysis of cell cycle phases demonstrated that the $0.01 \mu \mathrm{g} / \mathrm{mL}$ and $0.1 \mu \mathrm{g} / \mathrm{mL}$ AREG treatment groups had a slightly higher proliferation index $(\mathrm{PI}=$ $\mathrm{G} 2 / \mathrm{M}+\mathrm{S}$ ), in comparison with both the control group and the $1 \mu \mathrm{g} / \mathrm{mL}$ AREG-treatment group. Notably, flow cytometry analysis showed that treatment with $0.01-1 \mu \mathrm{g} / \mathrm{ml}$ AREG had minimal impact on the apoptosis of hDPSCs. These results are largely consistent with those of most current studies [29-32].

AREG is potentially ideally suited for use in tissue repair and regeneration applications as it is not only able to enhance proliferation but can also stimulate differentiation. These data are consistent with previous findings as AREG has been reported to induce the differentiation of neuronal PC12 cells [38] and it has also been shown to be more effective for human mammary epithelial differentiation than other EGFR ligands [39]. Similar results have been reported for human mammary myoepithelial cells [40]. Furthermore, previous studies have demonstrated that AREG can induce cell differentiation in a variety of cell types. In our study, AREG was shown to induce mineralized nodule formation in a dose-dependent manner, although the high dose of $1 \mu \mathrm{g} / \mathrm{mL}$ AREG induced a marked decrease. In addition, AREG also increased DSPP, BSP, RUNX2, and OCN expression. Combined these data indicated that AREG induced odontogenic differentiation of DPSCs in vitro.

The biomimetic NF-gelatin scaffolds used here provide an excellent resource for bone tissue engineering studies due to their physical architecture and chemical composition which is similar to natural bone ECM. These constructs exhibit excellent biocompatibility, mechanical stability, and enhancement of the osteogenic differentiation [22-23,41]. To clarify the role of AREG in regeneration and mineralization in vivo, the DPSC/NF-gelatin-scaffold composites with or without AREG treatment were subcutaneously implanted in nude mice for 4 weeks. Micro CT analysis was initially used to detect the content, density, and distribution of both bone tissue and mineralized hard tissue formed in the cell-scaffold composites. The quantitative analysis using Micro CT showed that BV/TV (Bone Volume to Tissue Volume), Tb.Th. (Trabecular Thickness), and Tb.N. (Trabecular Number) were markedly increased in the AREG-stimulated group, although the trabecular separationwas decreased. These findings indicate that AREG supplementation produced more newly mineralized tissue together with increased numbers and thicker bone trabeculae, and the trabecular structure was more compact. These data indicate that AREG can promote the formation of the mineralized tissue in vivo. Furthermore, both H\&E and Masson staining showed increased DPSC penetration into the pores of scaffold, with relatively large amounts of ECM and collagen fiber deposition and formation in the AREG group. Von Kossa staining indicated that biomineralization occurred in all the composites, with greater mineralized matrix and calcium salt deposition on the composites in the AREG treated group. This finding was consistent with the Micro CT quantitative analysis data. All the results demonstrated that AREG facilitated the formation of dentin-like matrix in DPSC/NF-gelatin-scaffold composites. Furthermore, the AREG over-expression experiments showed a similar promotion of odontogenic differentiation, whereas the knockdown experiments inhibited this process. These results indicated that AREG was necessary for odontoblastic differentiation of DPSCs and could facilitate the regeneration and mineralization of hDPSCs. It is yet to be determined but AREG may contribute substantially to injured pulp repair and regeneration. 
AREG plays a vital role in biological processes through its interaction with EGFR and tyrosine phosphorylation of downstream proteins, activating two major signaling pathways, the MAPK and PI3K/Akt pathways [42-43]. Interestingly, a previous study has shown that AREG interacts with EGFR, activating PI3K/Akt, and subsequently the NF-KB transcription factor on the MMP-13 promoter, inducing cartilage destruction in osteoarthritis [44]. MAPK signaling has also been observed to participate in AREGinduced morphological effects in MDCK cells [45] and AREG stimulation was found to be required for the differentiation of K5+K19-hMECs through activation of ERK and MAPK but not Akt signaling [39]. Moreover, inhibition of ERK1/2 blocked AREG-induced myoepithelial differentiation [40]. In the present study, ERK, JNK, MAPK, and AKT were phosphorylated in response to AREG stimulation, an action that was markedly antagonized by specific inhibitors of these proteins. In addition, the ERK, JNK, MAPK, and $\mathrm{PI}$ KK/Akt inhibitors also significantly reduced mineralized nodule formation and expression of protein mineralization markers. These data support the involvement of ERK, JNK, MAPK, and PI3K/AKT pathways in AREG-induced differentiation of hDPSCs.

\section{Conclusions}

In conclusion, our in vitro and in vivo data demonstrated that AREG was necessary for odontoblastic differentiation of DPSCs and facilitated the regeneration and mineralization of hDPSCs. Furthermore, the investigation of the roles of the MAPK and PI3K/AKT pathways in AREG-induced growth and osteo/odontogenic differentiation in hDPSCs indicated that activation of the ERK, JNK, MAPK and PI3K/AKT signaling pathways activation are involved in AREG-mediated differentiation of hDPSCs. Further investigation of these mechanisms may provide targets and treatment modalities for use in the repair of damaged and diseased pulp and for the regeneration of dental tissues.

\section{Abbreviations}

AREG: amphiregulin; MAPK: mitogen-activated protein kinase; PI3K phosphatidylinositol 3-kinase; ERK: extracellular signal-regulated kinase ; JNK: c-Jun N-terminal kinase; EGF: epidermal growth factor; DSPP: dentin sialophosphoprotein; RUNX2: Runt-related transcription factor 2; OCN: osteocalcin; and BSP: bone sialoprotein; NF-gelatin: nanofibrous gelatin; BV/TV: Bone Volume to Tissue Volume; Tb.Th.: Trabecular Thickness; Tb.N.: Trabecular Number; Tb.Sp..trabecular separation.

\section{Declarations}

\section{Ethics approval and consent to participate}

The study had approval from the Ethics Committee of the Fourth Military Medical University (FMMU), Xi'an, China, with informed consent. All animal surgical procedures were approved by the Animal Care Committee and the Institutional Review Board (IRB) for Human Subjects Research of the Fourth Military Medical University. 


\section{Consent for publication}

Not applicable.

\section{Availability of data and materials}

The authors confirm the availability of all data generated or analyzed in this manuscript.

\section{Competing interests}

The authors declared no potential conflicts of competing interest with respect to the research, authorship, and/or publication of this article.

\section{Funding}

This work was supported by National Natural Science Foundation of China (Grant 81771060ه81970932 and 81470733).

\section{Author Contributions}

Junqing Li, contributed to data acquisition, analysis, and interpretation, drafted and critically revised the manuscript; Zhihua Wang, contributed to design, the drafted manuscript and critically revised the manuscript; Juan Wang, contributed to design, the drafted manuscript and data acquisition; Qian Guo, Yi Fu, Zihan Dai, Minghao Wang, contributed to data acquisition and analysis; Yu Bai, Xin Liu, contributed to analysis and data interpretation. Paul Cooper, contributed to design and drafting, and critically revising the manuscript; Jiayuan Wu, Wenxi He, contributed to conception, design, data interpretation, and critical revisions of the manuscript. All authors gave final approval and agree to be accountable for all aspects of the work.

\section{Acknowledgments}

Not applicable.

\section{References}

1. Augello A, Kurth TB, De Bari C. Mesenchymal stem cells: a perspective from in vitro cultures to in vivo migration and niches. Eur Cell Mater. 2010;20:121-33. https://doi.org/10.22203/ecm.v020a11.

2. Kolios G, Moodley Y. Introduction to stem cells and regenerative medicine. Respiration. 2013;85(1):3-10. https://doi.org/10.1159/000345615. 
3. Gronthos S, Brahim J, Li W, Fisher LW, Cherman N, Boyde A, et al. Stem cell properties of human dental pulp stem cells. J Dent Res. 2002;81(8):531-5. https://doi.org/10.1177/154405910208100806.

4. Gronthos S, Mankani M, Brahim J, Robey PG, Shi S. Postnatal human dental pulp stem cells (DPSCs) in vitro and in vivo. Proc Natl Acad Sci U S A. 2000;97(25):13625-30. https://doi.org/10.1073/pnas.240309797.

5. d'Aquino R, Graziano A, Sampaolesi M, Laino G, Pirozzi G, De Rosa A, et al. Human postnatal dental pulp cells co-differentiate into osteoblasts and endotheliocytes: a pivotal synergy leading to adult bone tissue formation. Cell Death Differ. 2007;14(6):1162-71. https://doi.org/10.1038/sj.cdd.4402121.

6. Yu J, He H, Tang C, Zhang G, Li Y, Wang R, et al. Differentiation potential of STRO-1+ dental pulp stem cells changes during cell passaging. BMC Cell Biol. 2010;11:32. https://doi.org/10.1186/14712121-11-32.

7. Alge DL, Zhou D, Adams LL, Wyss BK, Shadday MD, Woods EJ ,et al. Donor-matched comparison of dental pulp stem cells and bone marrow-derived mesenchymal stem cells in a rat model. J Tissue Eng Regen Med. 2010;4(1):73-81. https://doi.org/10.1002/term.220.

8. Berasain C, Avila MA. Amphiregulin. Semin Cell Dev Biol. 2014;28:31-41. https://doi.org/10.1016/j.semcdb.2014.01.005.

9. Berasain C, García-Trevijano ER, Castillo J, Erroba E, Lee DC, PrietoJ,et al. Amphiregulin: an early trigger of liver regeneration in mice. Gastroenterology. 2005;128(2):424-32. https://doi.org/10.1053/j.gastro.2004.11.006.

10. Willmarth NE, Ethier SP. Autocrine and juxtacrine effects of amphiregulin on the proliferative, invasive, and migratory properties of normal and neoplastic human mammary epithelial cells. J Biol Chem. 2006;281(49):37728-37. https://doi.org/10.1074/jbc.M606532200.

11. Zuo WL, Yang J, Gomi K, Chao I, Crystal RG, Shaykhiev R. EGF-Amphiregulin Interplay in Airway Stem/Progenitor Cells Links the Pathogenesis of Smoking-Induced Lesions in the Human Airway Epithelium. Stem Cells. 2017;35(3):824-37. https://doi.org/10.1002/stem.2512.

12. Takenouchi T, Kadosaka M, Shin SY, Munekata E. Biological actions of the epidermal growth factorslike domain peptides of mouse schwannoma-derived growth factor and human amphiregulin. J Pept Res. 1999;53(2):120-5. https://doi.org/10.1034/j.1399-3011.1999.00004.x.

13. Raimondo S, Saieva L, Vicario E, Pucci M, Toscani D, Manno M, et al. Multiple myeloma-derived exosomes are enriched of amphiregulin (AREG) and activate the epidermal growth factor pathway in the bone microenvironment leading to osteoclastogenesis. J Hematol Oncol. 2019;12(1):2. https://doi.org/10.1186/s13045-018-0689-y.

14. Shoyab M, McDonald VL, Bradley JG, Todaro GJ. Amphiregulin: a bifunctional growth-modulating glycoprotein produced by the phorbol 12-myristate 13-acetate-treated human breast adenocarcinoma cell line MCF-7. Proc Natl Acad Sci U S A. 1988;85(17):6528-32. https://doi.org/10.1073/pnas.85.17.6528. 
15. Rosa V, Zhang Z, Grande RH, Nör JE. Dental pulp tissue engineering in full-length human root canals. J Dent Res. 2013;92(11):970-5. https://doi.org/10.1177/0022034513505772.

16. Huang GT, Gronthos S, Shi S. Mesenchymal stem cells derived from dental tissues vs. those from other sources: their biology and role in regenerative medicine. J Dent Res. 2009;88(9):792-806. https://doi.org/10.1177/0022034509340867.

17. Chen JC, Huang $\mathrm{C}$, Lee IN, Wu YP, Tang $\mathrm{CH}$. Amphiregulin enhances cell migration and resistance to doxorubicin in chondrosarcoma cells through the MAPK pathway. Mol Carcinog. 2018;57(12):181624. https://doi.org/10.1002/mc.22899.

18. Kato $M$, Inazu T, Kawai $Y$, MasamuraK, Yoshida $M$, Tanaka N, et al. Amphiregulin is a potent mitogen for the vascular smooth muscle cell line, A7r5. BiochemBiophys Res Commun. 2003;301(4):1109115. https://doi.org/10.1016/s0006-291x(03)00093-7.

19. Luo Z, Kohli MR, Yu Q, Kim S, Qu T, He WX. Biodentine induces human dental pulp stem cell differentiation through mitogen-activated protein kinase and calcium-/calmodulin-dependent protein kinase II pathways. J Endod. 2014;40(7):937-42. https://doi.org/10.1016/j.joen.2013.11.022.

20. He W, Wang Z, Luo Z, Yu Q, Jiang Y, Zhang Y, Zhou Z, et al. LPS promote the odontoblastic differentiation of human dental pulp stem cells via MAPK signaling pathway. J Cell Physiol. 2015;230(3):554-61. https://doi.org/10.1002/jcp.24732.

21. He W, Qu T, Yu Q, Wang Z, Lv H, Zhang J, et al. LPS induces IL-8 expression through TLR4, MyD88, NF-kappaB and MAPK pathways in human dental pulp stem cells. Int Endod J. 2013;46(2):128-36. https://doi.org/10.1111/j.1365-2591.2012.02096.x.

22. Qu T, Jing J, Ren Y, Ma C, Feng J, Yu Q, et al. Complete pulpodentin complex regeneration by modulating the stiffness of biomimetic matrix. Acta Biomater. 2015;16:60-70. https://doi.org/10.1016/j.actbio.2015.01.029.

23. He X, Jiang W, Luo Z, QuT, Wang Z, Liu N, et al. IFN-y regulates human dental pulp stem cells behavior via NF-KB and MAPK signaling. Sci Rep. 2017;7:40681. https://doi.org/10.1038/srep40681.

24. Mori G, Brunetti G, Oranger A, Carbone C, Ballini A, Lo Muzio L, et al. Dental pulp stem cells: osteogenic differentiation and gene expression. Ann N Y Acad Sci. 2011;1237:47-52. https://doi.org/10.1111/j.1749-6632.2011.06234.x.

25. Shirasawa S, Sugiyama S, Baba I, Inokuchi J, SekineS, Ogino K, et al. Dermatitis due to epiregulin deficiency and a critical role of epiregulin in immune-related responses of keratinocyte and macrophage. Proc Natl Acad Sci U S A. 2004;101(38):13921-6. https://doi.org/10.1073/pnas.0404217101.

26. Pastore S, Mascia F, Mariani V, Girolomoni G. The epidermal growth factor receptor system in skin repair and inflammation. J Invest Dermatol. 2008;128(6):1365-74. https://doi.org/10.1038/sj.jid.5701184.

27. Solic N, Davies DE. Differential effects of EGF and amphiregulin on adhesion molecule expression and migration of colon carcinoma cells. Exp Cell Res. 1997;234(2):465-76. https://doi.org/10.1006/excr.1997.3635. 
28. Hirota N, Risse PA, Novali M, McGovern T, Al-Alwan L, McCuaig S, et al. Histamine may induce airway remodeling through release of epidermal growth factor receptor ligands from bronchial epithelial cells. FASEB J. 2012;26(4):1704-16. https://doi.org/10.1096/fj.11-197061.

29. Liu B, Xia X, Zhu F, Park E, Carbajal S, Kiguchi K, et al. IKKalpha is required to maintain skin homeostasis and prevent skin cancer. Cancer Cell. 2008;14(3):212-25. https://doi.org/10.1016/j.ccr.2008.07.017.

30. Stoll SW, Johnson JL, Bhasin A, Johnston A, Gudjonsson JE, Rittié L, et al. Metalloproteinasemediated, context-dependent function of amphiregulin and HB-EGF in human keratinocytes and skin. J Invest Dermatol. 2010;130(1):295-304. https://doi.org/10.1038/jid.2009.211.

31. Stoll SW, Johnson JL, Li Y, Rittié L, Elder JT. Amphiregulin carboxy-terminal domain is required for autocrine keratinocyte growth. J Invest Dermatol. 2010;130(8):2031-40. https://doi.org/10.1038/jid.2010.98.

32. Cook PW, Mattox PA, Keeble WW, Pittelkow MR, Plowman GD, Shoyab M, et al. A heparin sulfateregulated human keratinocyte autocrine factor is similar or identical to amphiregulin. Mol Cell Biol. 1991;11(5):2547-57. https://doi.org/10.1128/mcb.11.5.2547-2557.1991.

33. Hurbin A, Dubrez L, Coll JL, Favrot MC. Inhibition of apoptosis by amphiregulin via an insulin-like growth factor-1 receptor-dependent pathway in non-small cell lung cancer cell lines. J Biol Chem. 2002;277(51):49127-33. https://doi.org/10.1074/jbc.M207584200.

34. Shao J, Lee SB, Guo H, Evers BM, Sheng H. Prostaglandin E2 stimulates the growth of colon cancer cells via induction of amphiregulin. Cancer Res. 2003;63(17):5218-23. https://doi.org/10.1002/yea.320080508.

35. Castillo J, Erroba E, Perugorría MJ, Santamaría M, Lee David C, Prieto J, et al. Amphiregulin contributes to the transformed phenotype of human hepatocellular carcinoma cells. Cancer Res. 2006;66(12):6129-38. https://doi.org/10.1158/0008-5472.CAN-06-0404.

36. Johnson GR, Saeki T, Gordon AW, Shoyab M, Salomon DS, Stromberg K. Autocrine action of amphiregulin in a colon carcinoma cell line and immunocytochemical localization of amphiregulin in human colon. J Cell Biol. 1992;118(3):741-51. https://doi.org/10.1083/jcb.118.3.741.

37. Funatomi H, Itakura J, Ishiwata T, Pastan I, Thompson SA, Johnson GR, et al. Amphiregulin antisense oligonucleotide inhibits the growth of T3M4 human pancreatic cancer cells and sensitizes the cells to EGF receptor-targeted therapy. Int J Cancer. 1997;72(3):512-7. https://doi.org/10.1002/(sici)10970215(19970729)72:3<512::aid-ijc21>3.0.co;2-c.

38. Kimura H, Schubert D. Schwannoma-derived growth factor promotes the neuronal differentiation and survival of PC12 cells. J Cell Biol. 1992;116(3):777-83. https://doi.org/10.1083/jcb.116.3.777.

39. Mukhopadhyay C, Zhao X, Maroni D, Band V, Naramura M. Distinct effects of EGFR ligands on human mammary epithelial cell differentiation. PLoS One. 2013;8(10):e75907. https://doi.org/10.1371/journal.pone.0075907.

40. Pasic L, Eisinger-Mathason TS, Velayudhan BT, MoskalukCA, Brenin DR, Macara IG, et al. Sustained activation of the HER1-ERK1/2-RSK signaling pathway controls myoepithelial cell fate in human 
mammary tissue. Genes Dev. 2011;25(15):1641-53. https://doi.org/10.1101/gad.2025611.

41. Liu X, Smith LA, Hu J, Ma PX. Biomimetic nanofibrous gelatin/apatite composite scaffolds for bone tissue engineering. Biomaterials. 2009;30(12):2252-8.

https://doi.org/10.1016/j.biomaterials.2008.12.068.

42. Toulany M, Baumann M, Rodemann HP. Stimulated PI3K-AKT signaling mediated through ligand or radiation-induced EGFR depends indirectly, but not directly, on constitutive K-Ras activity. Mol Cancer Res. 2007;5(8):863-72. https://doi.org/10.1158/1541-7786.MCR-06-0297.

43. Shankaran $\mathrm{H}$, Wiley HS. Oscillatory dynamics of the extracellular signal-regulated kinase pathway. CurrOpin Genet Dev. 2010;20(6):650-5. https://doi.org/10.1016/j.gde.2010.08.002.

44. Chen YT, Hou CH, Hou SM, Liu JF. The effects of amphiregulin induced MMP-13 production in human osteoarthritis synovial fibroblast. Mediators Inflamm. 2014;2014:759028. https://doi.org/10.1155/2014/759028.

45. Chung E, Graves-Deal R, Franklin JL, Coffey RJ. Differential effects of amphiregulin and TGF-alpha on the morphology of MDCK cells. Exp Cell Res. 2005;309(1):149-60. https://doi.org/10.1016/j.yexcr.2005.05.012.

\section{Figures}


A (a)
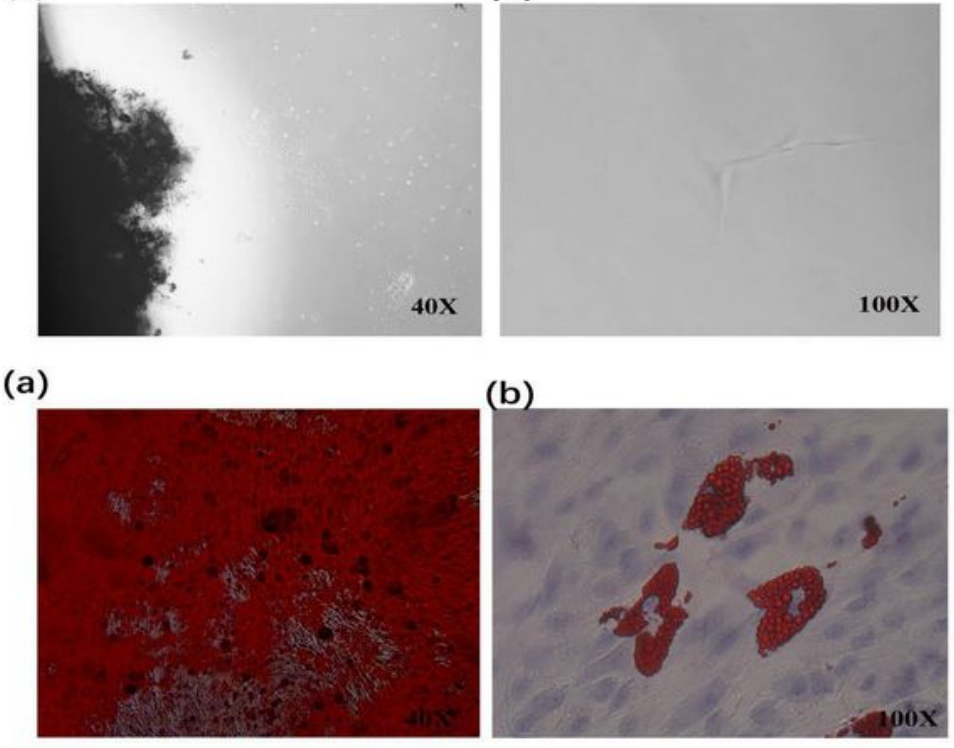

(b)

(c)

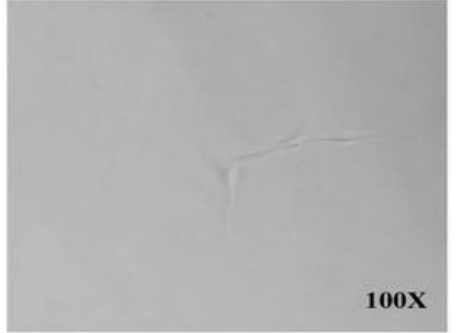

$40 x$

\section{C}

(a)

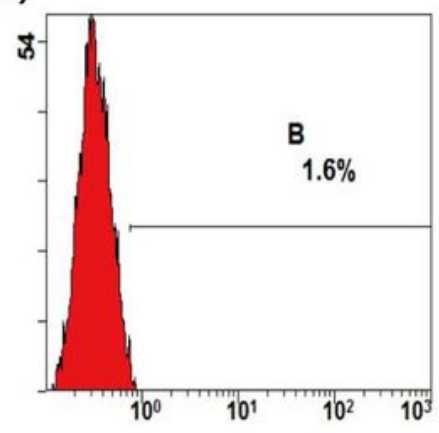

(e)

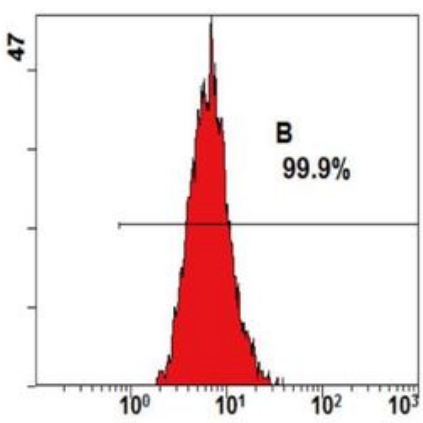

CD105 (b)

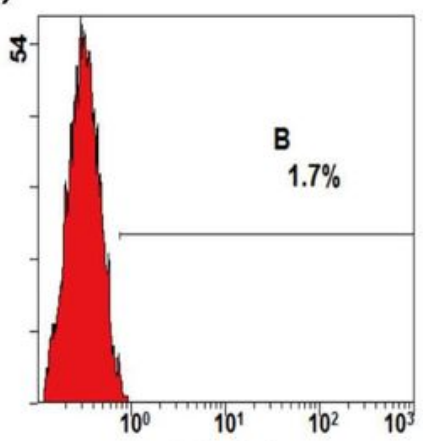

(f)

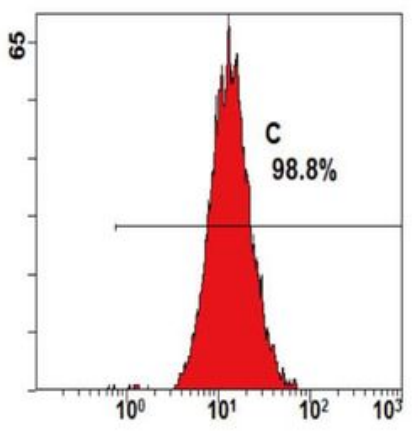

CD29 (c)

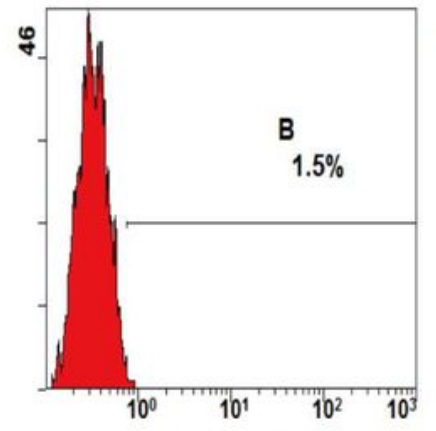

(g)

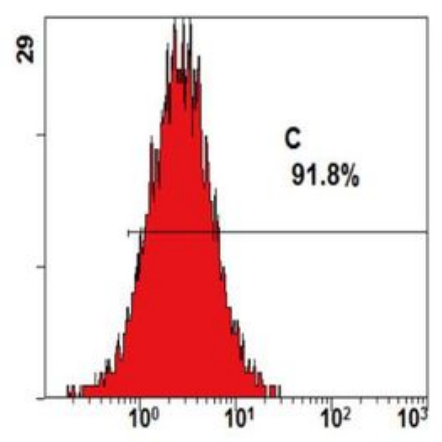

CD146 (d)

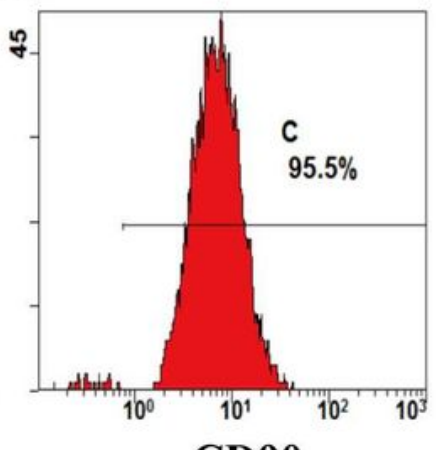

(h)
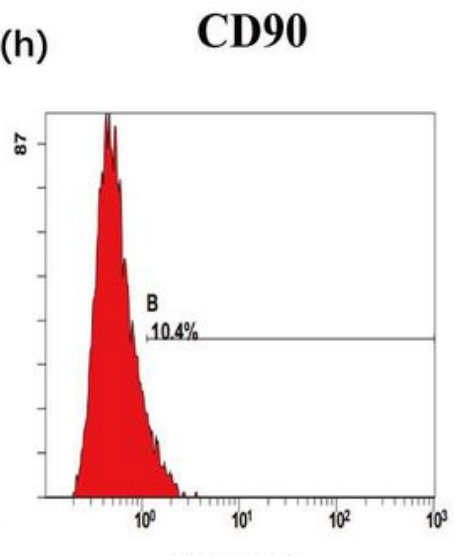

STR0-1

Figure 1

\section{Culture and characterization of DPSCs}

A. (a) DPSCs isolated and cultured from pulp tissue samples. (b) Clonal DPSCs. (c) were cultured for 2 weeks. B. (a) Mineralized nodule formation in osteo/odontogenic induction medium demonstrated by Alizarin Red staining. (b) Lipid droplet formation in adipogenic induction medium using Oil Red 0 
staining. C. Flow cytometry of molecular surface antigen markers in DPSCs. (a) negative control for DPSCs. Representative profiles are shown for the expression of immunophenotypic markers CD34 (b), CD45 (c), CD90 (d), CD105 (e), CD29 (f), CD146 (g) and STRO-1(h) in DPSCs.

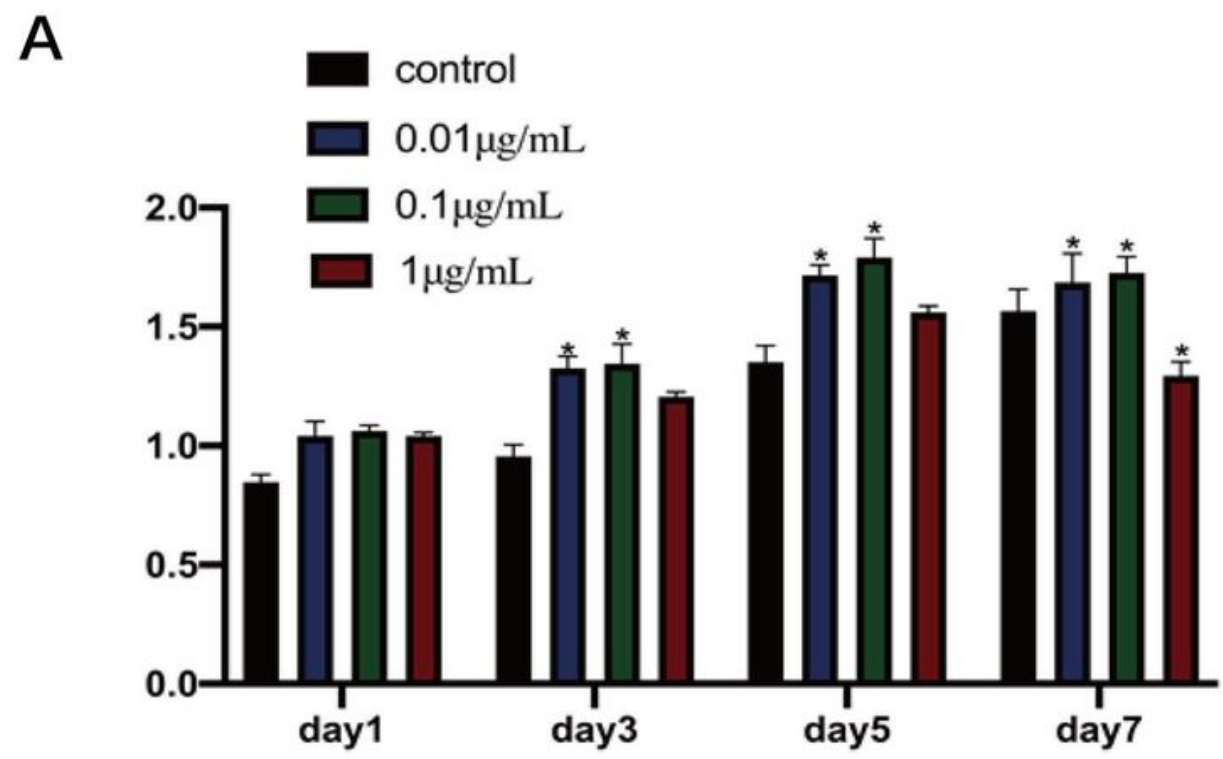

B

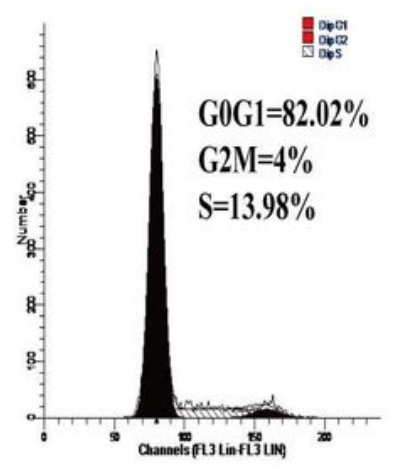

CTRL

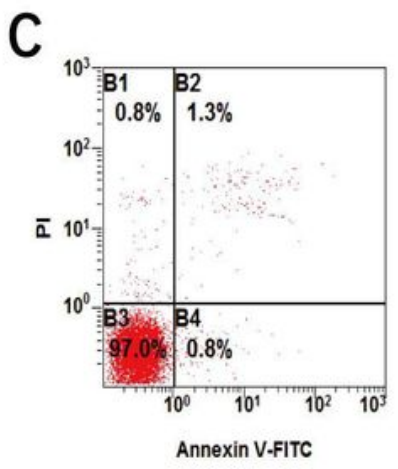

CTRL

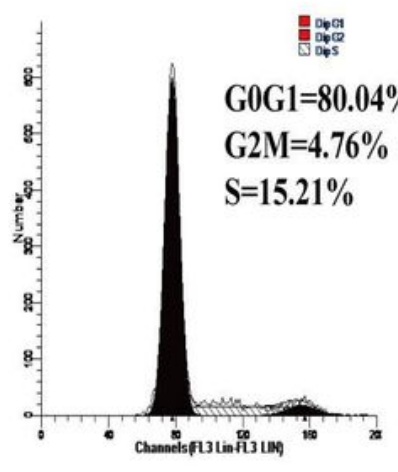

$0.01 \mu \mathrm{g} / \mathrm{mL}$ AREG

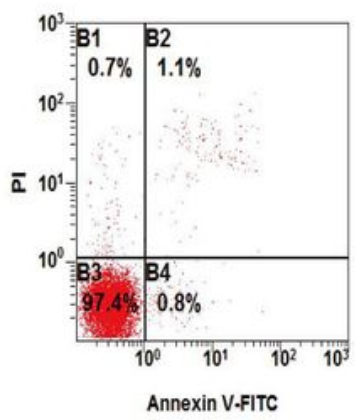

$0.01 \mu \mathrm{g} / \mathrm{mL}$ AREG

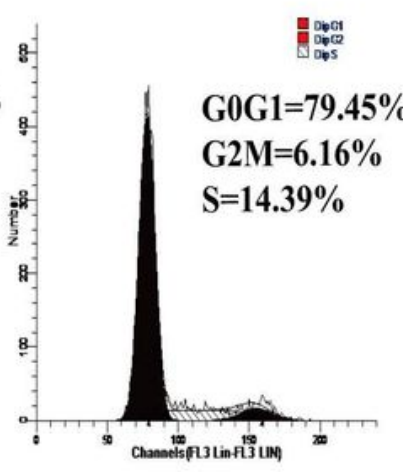

$0.1 \mu \mathrm{g} / \mathrm{mL}$ AREG

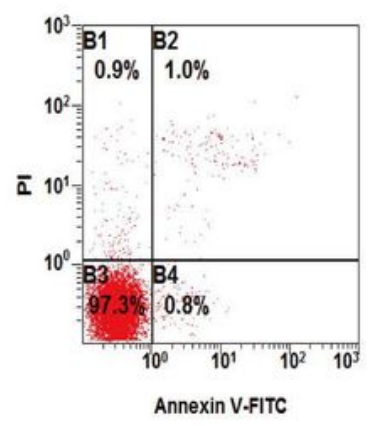

$0.1 \mu \mathrm{g} / \mathrm{mL}$ AREG

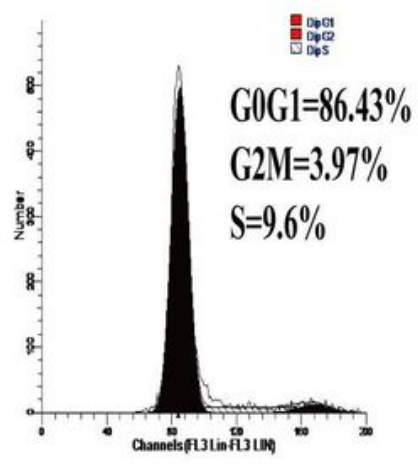

$1 \mu \mathrm{g} / \mathrm{mL}$ AREG

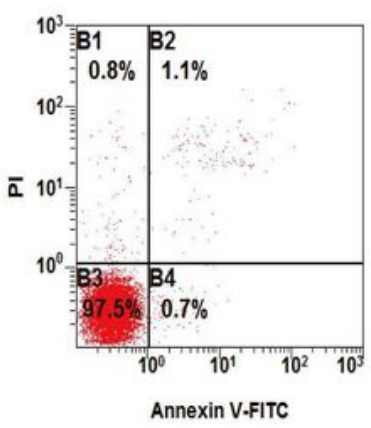

$1 \mu \mathrm{g} / \mathrm{mL}$ AREG

Figure 2

Effects of AREG on the growth of DPSCs. 
A.The CCK-8 assay was used to detect cell proliferation in different AREG-treated groups $(0.01-1 \mathrm{mg} / \mathrm{mL})$ and untreated DPSCs at $1,3,5$ and 7 days $(n=5, *=P<0.05)$. B. The cell cycle proliferation index $(P I=G 2 / M+S)$ in AREG-treated and control groups analyzed by flow cytometry. C. Flow cytometry analysis of AREG-treated and control groups.

A

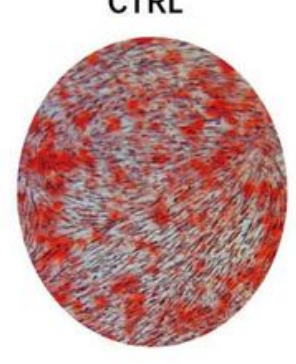

AREG $(\mu \mathrm{g} / \mathrm{mL})$

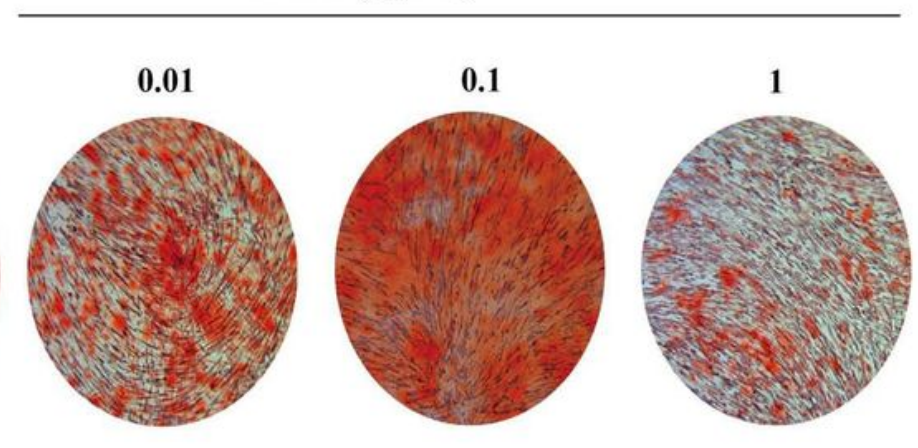

C
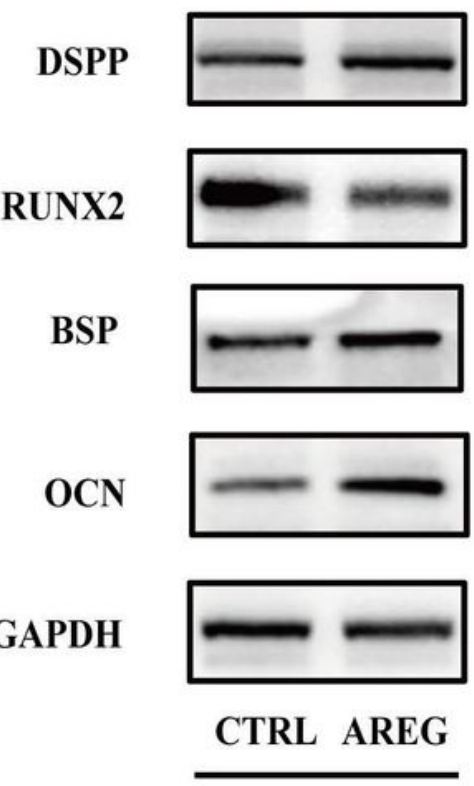

$3 d$
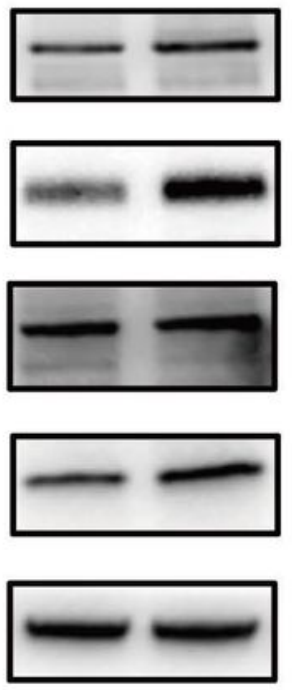

CTRL AREG

$7 d$
B

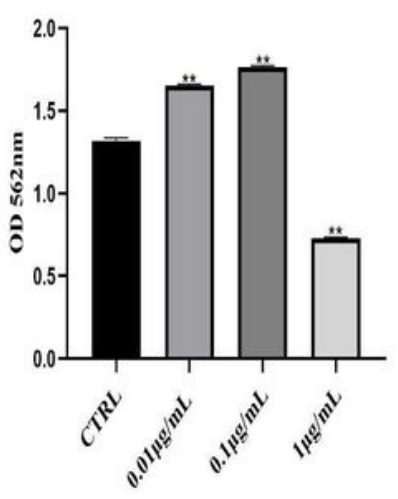

D
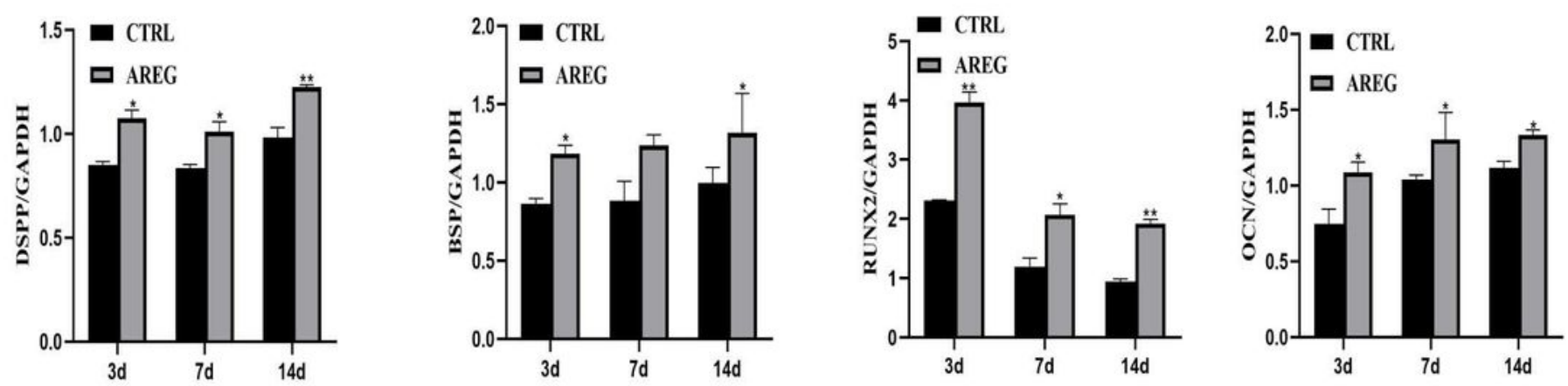

Figure 3 
AREG enhances the oriented differentiation potential of DPSCs. A. Alizarin Red S staining of DPSCs after 14 days' culture with different AREG concentrations in mineralizing medium. B. Quantitative analysis of Alizarin Red S staining $\left(n=5,{ }^{* *}=P<0.05\right)$. C. Western blot analysis showing expression of the odontoblastic markers DSPP, RUNX2, BSP, and OCN. The full-length gels and blots are included in in Supplementary Figure.1A. D. ImageJ software analysis of the gray level of the panel. Data are expressed as means and $S D s, n=3, * P<0.05, * * P<0.01$. 
A (a)

CON

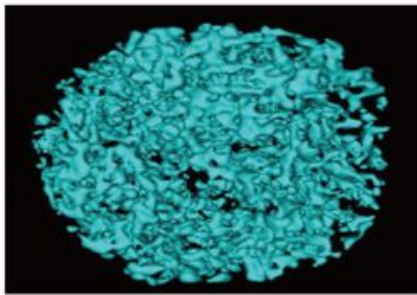

(b)

AREG

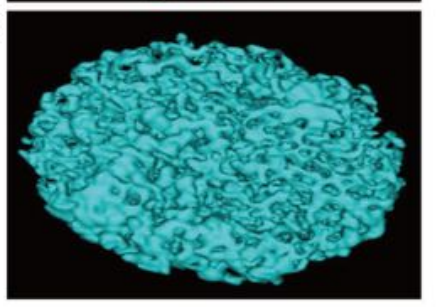

B (a)

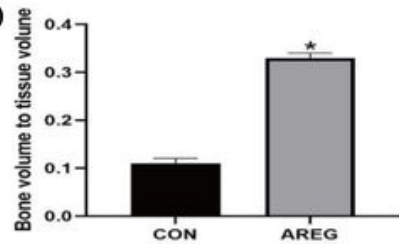

(c)

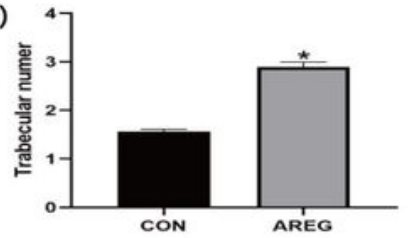

(b)

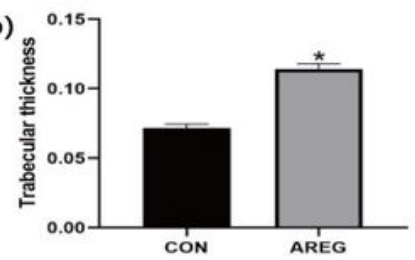

(d)

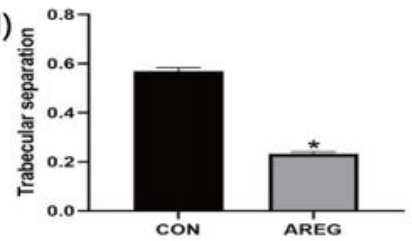

C

CON
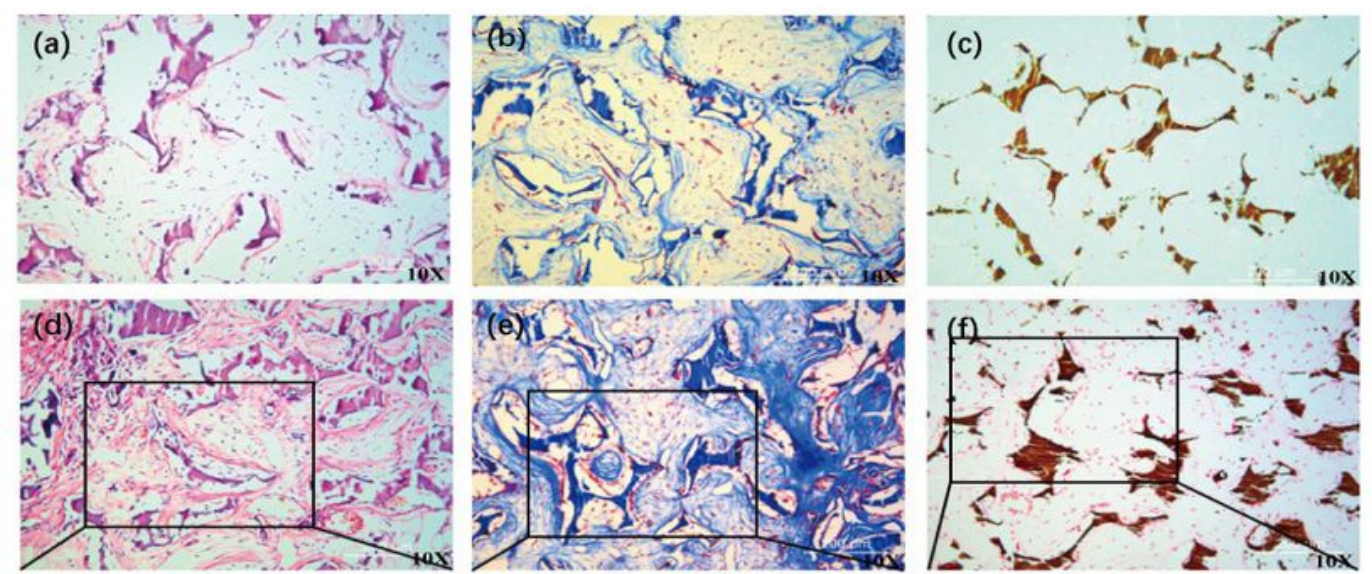

AREG
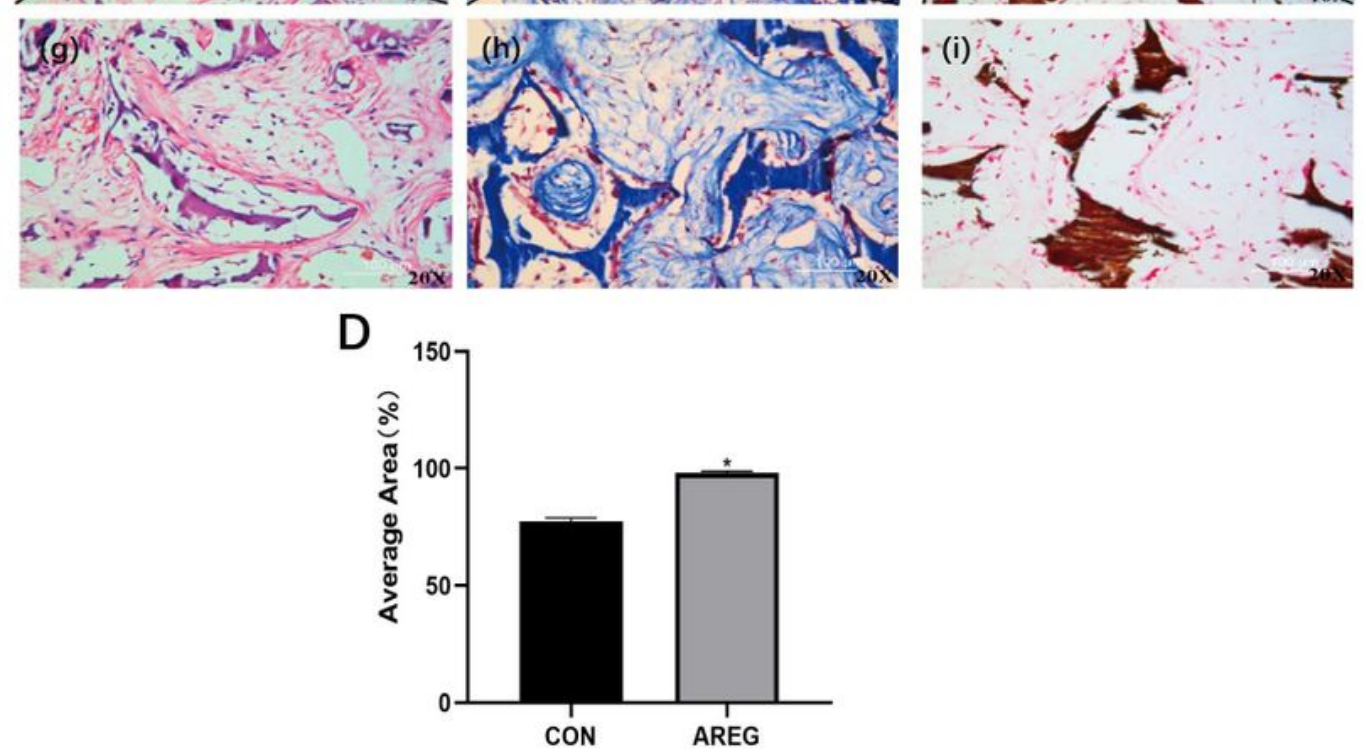

Figure 4

The effect of AREG on the regeneration and mineralization of hDPSCs in vivo A.

Micro-CT images of the DPSC/S-scaffold construct in nude mice after subcutaneous implantation for 4 weeks. A. (a) and (b) show the DPSC/NF-gelatin-scaffold composites of the control and AREG group, respectively. B. Quantitative analysis of Micro-CT images (a) BV/TV (Bone Volume to Tissue Volume); (b) 
Tb.Th. (Trabecular Thickness); (c) Tb.N. (Trabecular Number); (d) Tb.Sp. (Trabecular Separation). C. Histological staining of the DPSC/S-scaffold construct after nude mice subcutaneous implantation for 4 weeks. (a, d, g) H\&E staining; (b, e, h) Masson staining; (c, f, i) Von Kossa staining. ${ }^{*}=P<0.05$ represents a significant change compared with the control.

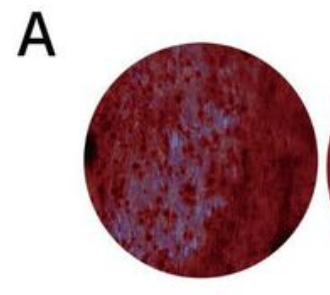

CTRL

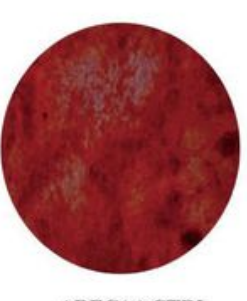

AREG(+) CTRL

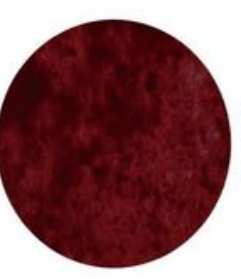

AREG(+)

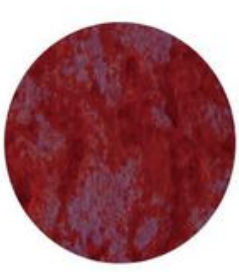

AREG(-) CTRL

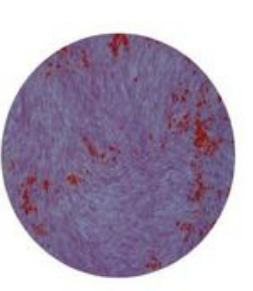

AREG(-)
B

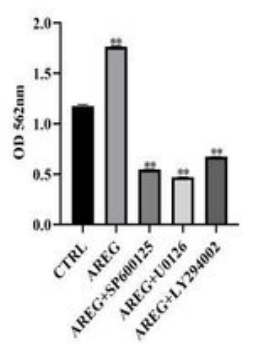

C
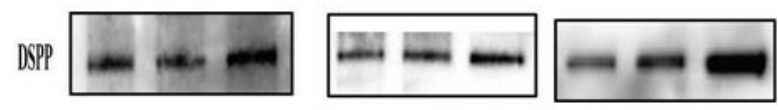

D
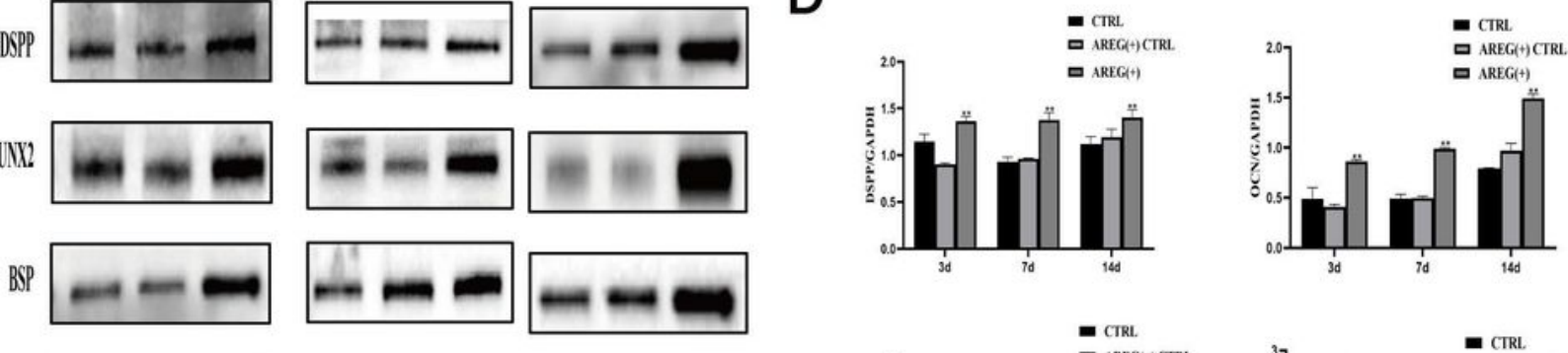

$\Gamma$

- CTRL.
ㅁ AREG $(+)$ CTRL ㅁ AREG $(+)(+2)$
- CTRL. ㅁ $\operatorname{AREG}(+)$ CTRL

Figure 5 


\section{The effects of AREG overexpression/knockdown on the differentiation of DPSCs.}

A. Alizarin Red S staining showing mineralized nodule formation in the AREG(+) and AREG (-) groups. B. Quantitative analysis of $A\left(n=5,{ }^{*} \mathrm{P}<0.05\right)$. C. Protein expression of odontoblastic markers DSPP, RUNX2, BSP, and OCN shown by Western blotting in the AREG (+) group. The full-length gels and blots are included in Supplementary Figure.1B. D. ImageJ analysis of the gray level of the panel. E. Protein expression of odontoblastic markers DSPP, RUNX2, BSP, and OCN shown by Western blotting in the AREG (-) group. The full-length gels and blots are included in Supplementary Figure.1C. F. ImageJ was used to analyze of the gray level of the panel. Data represent means and $S D s, n=3, *=P<0.05, * \star=P<0.01$.

\section{Figure 6}

\section{AREG promotes differentiation of DPSCs by activation of the ERK, JNK, and AKT pathways.}

A. Protein levels of ERK and p-ERK, JNK and p-JNK, p38 and p-p38, and ATK and p-AKT treated with AREG at different time points $(0,30,60$, and $90 \mathrm{~min})$ shown by Western blotting in DPSCs. The full-length gels and blots are included in Supplementary Figure.2A. B. Quantitative analysis of the gray intensity of A. C. Treatment of DPSCs with specific ERK, JNK, or PI3K inhibitors (U0126, SP600125, and LY294002, respectively). Protein levels of ERK and p-ERK, JNK and p-JNK, p-AKT/AKT are shown by Western blotting at the indicated times. The full-length gels and blots are included in Supplementary Figure.2B. D. Quantitative analysis of the ratio of $p$-ERK/ERK, p-JNK/JNK and p-AKT/AKT from C. E. Alizarin Red S staining showing mineralized nodule formation in DPSCs treated with the specific inhibitors. F. Quantitative analysis of Alizarin Red $S$ staining $\left(n=5,{ }^{*}<0.05\right)$. G. Western blots showing protein expression of odontoblastic markers (DSPP, RUNX2, BSP, and OCN) in different groups at day 14. The fulllength gels and blots are included in Supplementary Figure.2C. H. Quantitative analysis of data presented in $\mathrm{G}$. Data represent means and SDs, $n=3, *=P<0.05, * *=P<0.01$.

\section{Supplementary Files}

This is a list of supplementary files associated with this preprint. Click to download.

- supplementaryfiles1.docx 